\title{
INTERPOLATOR DALAM PEMBUATAN KONTUR PETA BATIMETRI
}

\section{(INTERPOLATOR IN BATHYMETRIC MAP CONTOURING)}

\author{
Vincentius P. Siregar ${ }^{1}$ dan Muhammad Banda Selamat ${ }^{2}$ \\ ${ }^{1}$ Seameo Biotrop, Jl.Raya Tajur KM 6 P.O Box 116, Bogor \\ Email:vincents@biotrop.org \\ ${ }^{2}$ Jurusan Ilmu Kelautan, Fakultas Ilmu Kelautan dan Perikanan, Universitas Hasanuddin \\ Email:mbandas2006@yahoo.com
}

\begin{abstract}
A digital bathymetric model may be produced after sounding point interpolated by using specific methods. There are three common interpolation methods used recently: inverse distance to power, kriging and minimum curvature. This study applied two scenarios of data processing to compare those three methods on producing bathymetric contours. Numeric validation was performed on the three different gridding methods. The result of this study showed that kriging method was spatially more effective in interpolating water depth than that of the other two.
\end{abstract}

Keywords: interpolation, kriging, inverse distance to power, minimum curvature, bathymetry

\section{ABSTRAK}

Suatu model batimetri digital dapat dibangun melalui interpolasi sejumlah besar titik kedalaman hasil pemeruman. Studi ini menggunakan dua skenario pengolahan yaitu menggunakan keseluruhan data perum dan menggunakan data perum terpilih. Pada setiap skenario pengolahan data, ada tiga metode interpolasi yang dibandingkan yaitu metode inverse distance to power, kriging dan minimum curvature. Nilai RMSE yang didapatkan dari masing-masing interpolator pada setiap skenario tersebut ternyata cukup bervariasi. Secara umum metode Kriging lebih efektif digunakan untuk menghasilkan gambar kontur kedalaman perairan dibandingkan dengan metode lainnya. Hasil studi ini memperlihatkan perlunya penanganan data agar pola suatu unsur spasial (kontur kedalaman) dapat ditampilkan secara lebih baik.

Kata Kunci: interpolasi, kriging, inverse distance to power, minimum curvature, batimetri

\section{PENDAHULUAN}

Model terrain digital adalah model matematik dari suatu permukaan bumi (termasuk dasar suatu perairan). Untuk dapat menggambarkan bentuk permukaan bumi, satu atau beberapa fungsi matematika diterapkan sesuai dengan karakter data titik pengukuran. Fungsi matematika ini sering disebut sebagai fungsi interpolasi ( $\mathrm{Li}$ et al., 2005). Interpolasi digunakan dalam pemodelan terrain digital untuk menentukan nilai tinggi suatu titik dari titik tetangga yang telah diketahui nilainya.

Suatu model batimetri digital yang menggambarkan topografi dasar perairan dapat dibangun dari operasi interpolasi sejumlah besar titik 
kedalaman hasil pemeruman. Surfer adalah suatu program pemetaan yang dapat dengan mudah melakukan interpolasi data hasil survei untuk membentuk kontur dan permukaan 3D (Yang et al., 2004). Terdapat dua belas metode interpolasi pada perangkat lunak ini, masing-masing memiliki fungsi spesifik dan parameter tersendiri.

Kesalahan sehubungan dengan perhitungan dan pengukuran dapat diindikasikan dari presisi dan akurasinya. Presisi mengacu pada sebaran dari ulangan bacaan dari suatu alat yang mengukur besaran fisik tertentu, sementara akurasi mengacu pada kedekatan angka pengukuran terhadap angka sebenarnya (Chapra dan Canale, 1991).

Kriging adalah interpolator geostatistik yang paling sering digunakan pada berbagai bidang ilmu. Kriging dapat menghubungkan titik-titik bernilai ekstrim tanpa mengisolasinya sehingga tidak terbentuk efek "mata sapi". Kriging pada perangkat lunak Surfer dapat difungsikan sebagai interpolator yang eksak atau sebagai penghalus, bergantung pada parameter yang digunakan (Keckler, 1994). Menurut van Beers dan Kleijnen (2004), hasil prediksi Kriging lebih akurat daripada metode regresi. Metode ini membolehkan error yang berkorelasi, sehingga semakin dekat nilai masukan, semakin kuat korelasi keluaran. Regresi menggunakan satu himpunan parameter estimasi untuk semua nilai masukan, sementara Kriging mengadaptasi parameternya (pembobotan) untuk memprediksi perubahan nilai masukan.

Metode Kriging memiliki beberapa keunggulan, antara lain (Largueche, 2006): Sebagai interpolator, metode Kriging memadukan korelasi spasial antar data, hal mana tidak di lakukan oleh prosedur statistik klasik. Keunggulan Kriging dibandingkan teknik konturisasi lainnya adalah kemam- puannya untuk mengkuantifikasi variansi dari nilai yang diestimasi sehingga tingkat presisi dari hasil estimasi dapat diketahui. Metode Kriging tetap dapat digunakan meskipun tidak ditemukan korelasi spasial antar data. Pada pengamatan yang saling bebas, proses estimasi Kriging akan mirip dengan estimasi menggunakan analisa regresi kuadrat terkecil. Kelemahan Kriging diantaranya adalah: banyaknya metode yang membangun teknik ini, sehingga menghendaki banyak asumsi yang jarang sekali dapat dipenuhi. Kriging mengasumsikan data menyebar normal sementara kebanyakan data lapangan tidak memenuhi kondisi tersebut. Selain itu, semi variogram yang dihitung untuk suatu himpunan data tidak berlaku untuk himpunan data lainnya. Dengan demikian estimasi semi variogram akan sulit bila titik sampel yang digunakan tidak mencukupi.

Metode inverse distance to a power (IDP) adalah interpolator yang menggunakan pembobotan jarak dari titik (Keckler, 1994). Asumsi yang berlaku pada metode ini adalah bahwa nilai suatu titik yang diinterpolasi sangat dipengaruhi oleh titik-titik yang lebih dekat dengan titik tersebut daripada titiktitik yang letaknya jauh. Suatu titik data dibobot selama proses interpolasi sedemikian rupa sehingga pengaruh satu titik ke titik lainnya berkurang sesuai dengan jaraknya. Semakin kuat peran pembobotan, semakin dekat jarak titik yang digunakan untuk aproksimasi nilai titik grid. Bila kekuatannya diperkecil, bobot akan tersebar lebih merata pada titik-titik tetangga. Salah satu ciri dari IDP adalah munculnya efek "mata sapi" di sekitar posisi pengamatan. Parameter penghalus dapat digunakan untuk mereduksi efek tersebut (Yang et al., 2004).

Minimum Curvature digunakan secara luas pada bidang ilmu kebumian. 
Permukaan yang diinterpolasi dengan metode ini, dapat dianalogikan dengan bidang elastis yang dihamparkan ke seluruh titik data sedemikian sehingga hanya sedikit lekukan yang terjadi. Minimum Curvature membuat permukaan sehalus mungkin untuk data yang diinterpolasi sehingga bukan merupakan interpolator yang eksak (Keckler, 1994).

Shamsudduha (2007) membandingkan berbagai prosedur interpolasi guna mendapatkan metode prediksi yang paling cocok untuk estimasi konsentrasi arsenik akuifer dangkal di Bangladesh. Hasil prediksi dievaluasi berdasarkan validasi silang, kesalahan perdiksi ratarata, dan root mean square. Disimpulkan bahwa Kriging memberikan nilai prediksi spasial yang lebih baik. Metode inverse distance memberikan hasil estimasi yang cukup realistis, namun variansi prediksinya paling tinggi dibandingkan metode lainnya

Studi ini bertujuan membandingkan tiga metode interpolasi pada perangkat lunak Surfer untuk pembuatan kontur batimetri. Ketiga metode tersebut adalah metode Kriging, metode kebalikan jarak terbobot atau inverse distance to power, dan metode minimum curvature. Hasil penelitian ini diharapkan dapat memberikan informasi tentang efektifitas dari ketiga metode itu.

\section{BAHAN DAN METODE}

Secara skematis, langkah-langkah dalam studi ini disajikan pada diagram alir dibawah ini (Gambar 1). Studi ini menggunakan data pemeruman hasil survei batimetri yang dilaksanakan pada tanggal 23-28 Juli 2008 di perairan Karang Congkak, Kepulauan Seribu (Gambar 2). Data perum ini telah dikoreksi dari pengaruh pasang surut sehingga nilai yang diperoleh adalah nilai kedalaman yang dianggap benar. Data tersebut kemudian dikelompokkan menjadi dua yaitu data awal dan data terseleksi. Data awal (DA) adalah keseluruhan data perum yang berjumlah 274 data, sementara Data terseleksi (DS) adalah data yang dipilih sedemikian rupa agar mewakili potongan melintang dari kontur batimetri lokasi studi (Gambar 2b dan 2c). Data ini kemudian diolah dengan menggunakan 2(dua) skenario sebagai berikut:

1) Peta kontur kedalaman dihasilkan dari interpolasi keseluruhan data perum (DA) dengan menggunakan tiga metoda interpolator.

2) Peta kontur kedalaman dihasilkan dari interpolasi data perum yang telah diseleksi (DS) dengan menggunakan tiga metoda interpolator.

Untuk kedua himpunan data tersebut (DA dan DS), interpolasi dilakukan dengan menggunakan ukuran sel dan perangkat lunak yang sama, dimana proses yang terjadi dianggap sebagai 'black box'. Studi ini hanya fokus pada hasil dari ketiga interpolator.

Sejumlah sampel uji dari titik pengamatan diambil untuk dibandingkan nilainya (pada lokasi geografi yang sama) dengan nilai hasil interpolasi. Pengambilan sampel diwakili oleh nomor lokasi (stasiun) dan untuk keperluan itu, sejumlah 30 bilangan acak dibangkitkan pada batas nilai yang disesuaikan dengan banyaknya data perum. Perbandingan antara nilai lapangan dengan nilai interpolasi dilakukan dengan menggunakan rumus:

$$
R M S E=\sqrt{\frac{\left(\sum_{i=1}^{n}\left(a_{i}-b_{i}\right)^{2}\right)}{n}}
$$

dimana $a_{\mathrm{i}}=$ nilai lapangan dan $\mathrm{b}_{\mathrm{i}}=$ nilai interpolasi. Distribusi $\left(a_{i}-b_{i}\right)^{2}$ disajikan dalam bentuk grafik untuk dapat dilihat distribusi kesalahan yang sekaligus menggambarkan tingkat akurasi dari masing-masing interpolator. 


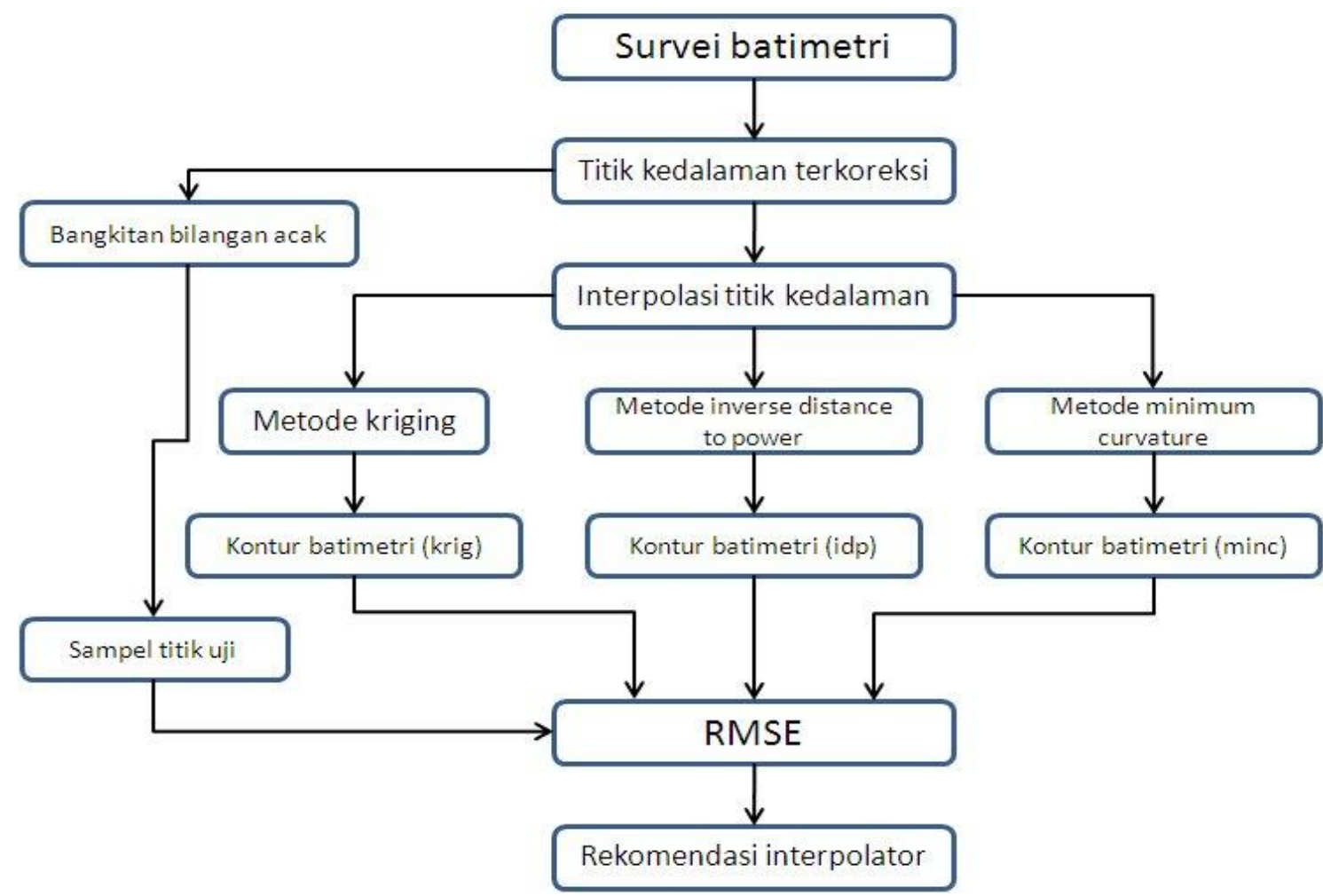

Gambar 1. Diagram alir studi akurasi interpolator dalam pembuatan kontur

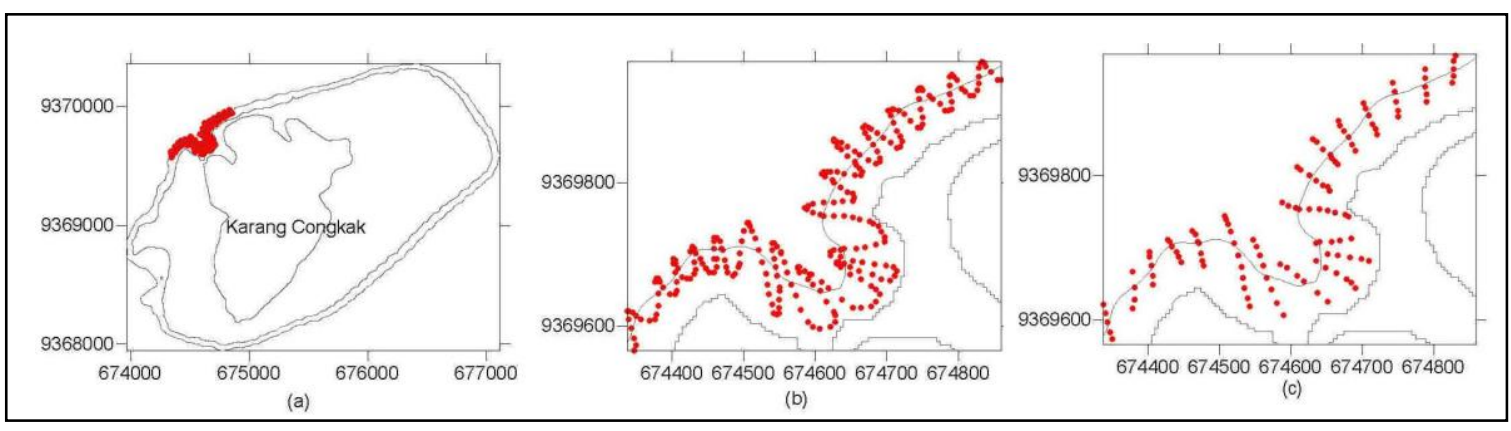

Gambar 2. Data batimetri yang digunakan untuk studi a) lokasi pemeruman, b) data awal pemeruman (DA), c) data perum yang telah diseleksi (DS).

\section{HASIL DAN PEMBAHASAN}

\subsection{Interpolasi Menggunakan Data Awal (DA)}

Sejumlah 274 data perum telah diinterpolasi pada ukuran grid 5 meter menggunakan tiga interpolator seperti yang telah disebutkan sebelumnya, yang merupakan implementasi skenario satu pada studi ini. Kontur hasil interpolasi untuk masing-masing metode tersebut disajikan pada Gambar 3a, 3b dan 3c. Dari Gambar 3a dapat dilihat bahwa metode Kriging menghasilkan garis kontur yang menyerupai 'rambut keriting' pada lintasan titik perum berbentuk zigzag. Bentuk kontur seperti ini terlihat tidak alami dan terkesan 'over estimated'. Pada Gambar 3b, efek 'mata sapi' yang menjadi ciri dari metode inverse distance power terlihat jelas pada 
titik-titik akhir lajur perum. Hasil interpolasi dari metode ini tidak memperlihatkan garis kontur kedalaman yang tegas seperti kedua metode lainnya. Gambar 3c memperlihatkan kontur kedalaman hasil interpolasi minimum curvature, dimana garis-garis kontur yang terbentuk pada titik-titik perum memiliki pola yang hampir sama dengan kontur dari metode Kriging.

Variasi nilai kesalahan (kuadrat) dari sejumlah titik uji untuk masingmasing interpolator disajikan pada Gambar 4a, b dan c. Dari gambar tersebut dapat dijelaskan bahwa variasi kuadrat kesalahan terkecil ditemukan pada metode inverse distance to power oleh karena sangat sedikit ditemukan 'spike' sebagai akibat dari besarnya variasi kuadrat kesalahan dari titik nol. Nilai root mean square error (RMSE) terkecil juga dihasilkan oleh metode inverse distance to power, namun tidak berbeda secara signifikan dengan metode lainnya (Gambar 5). Nilai RMSE untuk ketiga metode cukup besar, yaitu antara 1.3 hingga 1.4 meter dari nilai kedalaman pengukuran, sehingga perlu dipertimbangkan untuk menerapkan skenario lain dalam menghasilkan kontur batimetri.

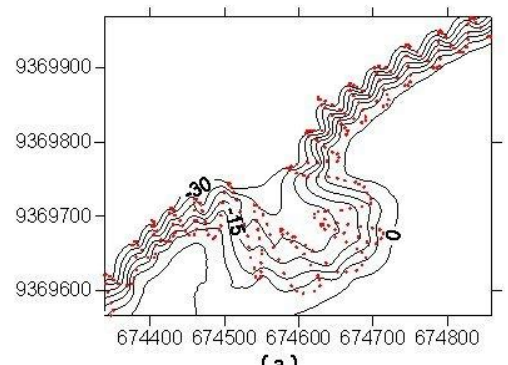

(a)

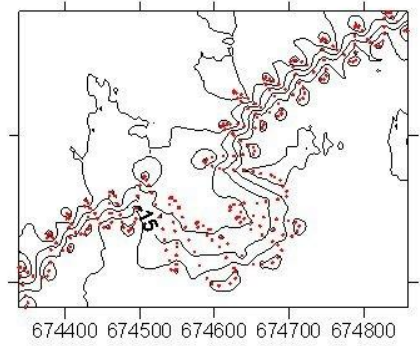

(b)

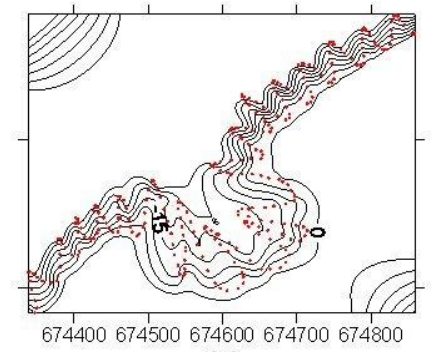

(c)

Gambar 3. Kontur batimetri hasil interpolasi data awal (DA) yang ditumpang susun dengan titik perumnya: a) metode Kriging, b) metode inverse distance to power, c) metode minimum curvature.

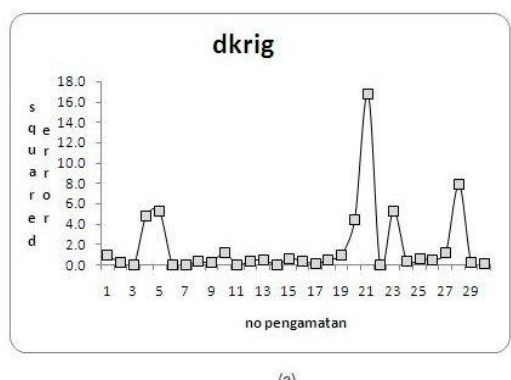

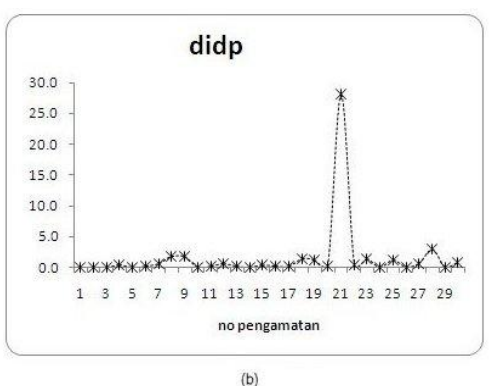

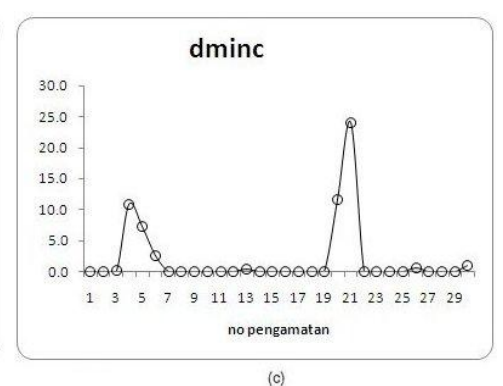

Gambar 4. Distribusi nilai kesalahan kuadrat hasil interpolasi dari sejumlah titik uji untuk data awal pemeruman (DA): a) metode Kriging, b) metode inverse distance to power, dan c) metode minimum curvature. 


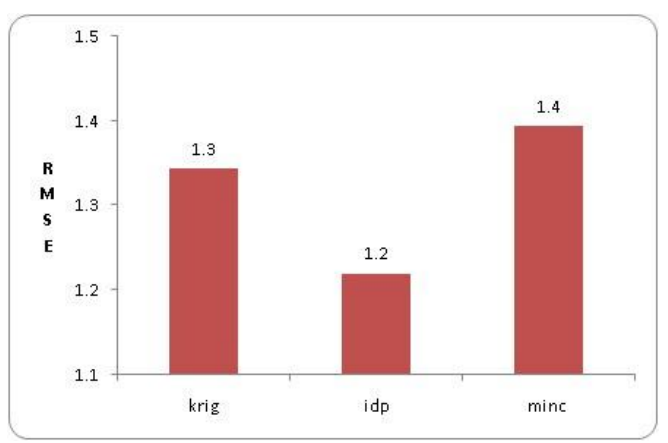

Gambar 5. RMSE kedalaman interpolasi dari tiga interpolator pada skenario 1.

\subsection{Interpolasi Menggunakan Data Terseleksi (DS)}

Skenario 2 menggunakan ketiga
metode interpolasi tersebut untuk
sejumlah 122 titik kedalaman hasil
seleksi dari data awal pemeruman.
Kontur hasil interpolasi tersebut disajikan pada Gambar 6a, b dan c. Secara umum dari sudut pandang kartografi, kontur kedalaman yang dihasilkan oleh metode Kriging (lihat gambar 6a) memberikan tampilan terbaik dibandingkan dengan metode lainnya. Efek 'rambut keriting' yang semula terlihat pada Gambar 3a berkurang dan transisi kedalaman mulai dari garis kontur nol hingga ke kontur yang lebih dalam menjadi lebih realistis untuk diterima sebagai suatu pendekatan kondisi lapangan.

Dengan skenario 2 ini terlihat gambaran kontur kedalaman dari metode Kriging sekilas tidak berbeda dengan hasil interpolasi metode minimum curvature (Gambar 6c). Namun bila diperhatikan secara seksama, pada metode minimum curvature jarak garis kontur nol ke kontur lainnya terlihat lebih rapat dan lebih berliku. Hasil interpolasi metode inverse distance to power (Gambar 6b) terlihat menyajikan efek 'mata sapi' yang lebih banyak dibandingkan dengan skenario 1 , sehingga menyulitkan penelusuran informasi kedalaman perairan. Fakta- fakta ini menunjukkan bahwa pertimbangan tampilan kartografis harus ikut diperhatikan dalam pembuatan kontur batimetri suatu perairan.

Ditinjau dari nilai kesalahan kuadrat yang dihasilkan oleh ketiga interpolator pada skenario $2 \mathrm{ini}$, metode minimum curvature memberikan penyimpangan terkecil (Gambar 7c). Variasi yang terjadi disetiap metode cenderung lebih kecil, dan penyimpangan nilai interpolasi terbesar tetap ditemukan pada metode Kriging (Gambar 7a). Kondisi ini diperkuat oleh hasil RMSE yang diberikan oleh ketiga interpolator tersebut (Gambar 8), dimana terlihat terjadinya penurunan nilai RMSE yang dengan kata lain meningkatkan akurasi nilai interpolasi. Interpolator yang paling akurat pada kasus ini adalah minimum curvature karena dapat memberikan RMSE senilai 0,1 .

\subsection{Faktor-faktor yang Menentukan Pemilihan Interpolator}

Banyaknya data yang diinterpolasi bukan semata-mata faktor yang mempengaruhi pemilihan metode interpolasi dalam pembuatan kontur kedalaman. Distribusi titik perum, ternyata juga merupakan faktor yang harus diperhatikan. Selain itu, lajur perum berbentuk zig-zag sebagai penerapan dari desain lajur sistematis, kadang kala tidak 


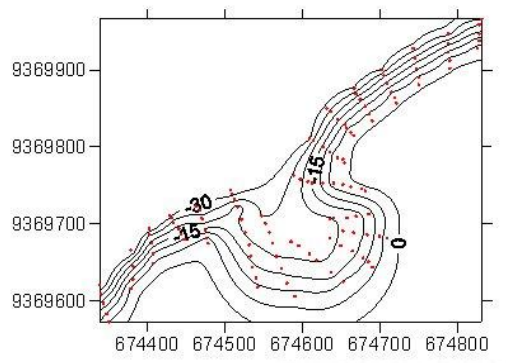

(a)

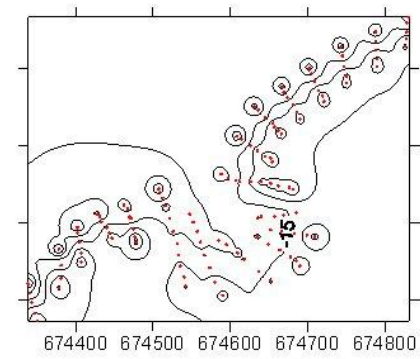

(b)

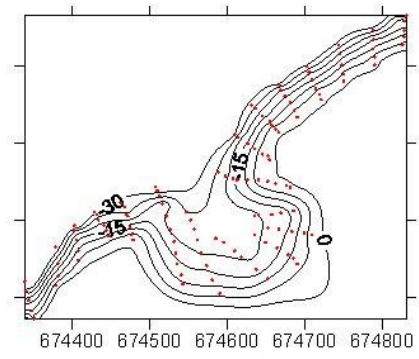

(c)

Gambar 6. Kontur batimetri hasil interpolasi data terseleksi (DS) yang ditumpang susun dengan titik perumnya: a) metode Kriging, b) inverse distance to power, c) metode minimum curvature.

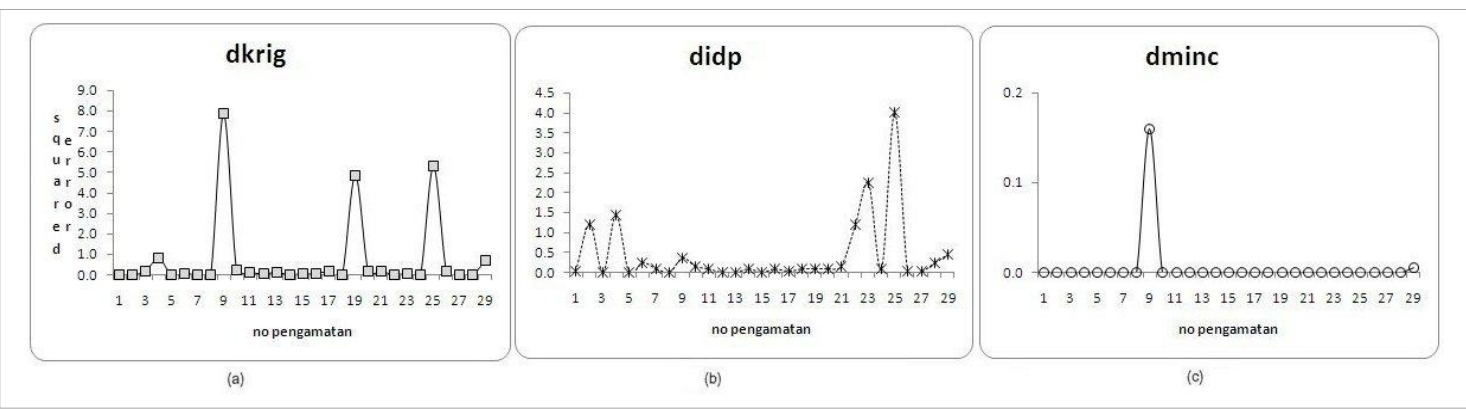

Gambar 7. Distribusi kesalahan kuadrat hasil interpolasi dari sejumlah titik uji untuk data perum yang diseleksi (DS): a) metode kriging, b) metode inverse distance to power, dan c) metode minimum curvature.

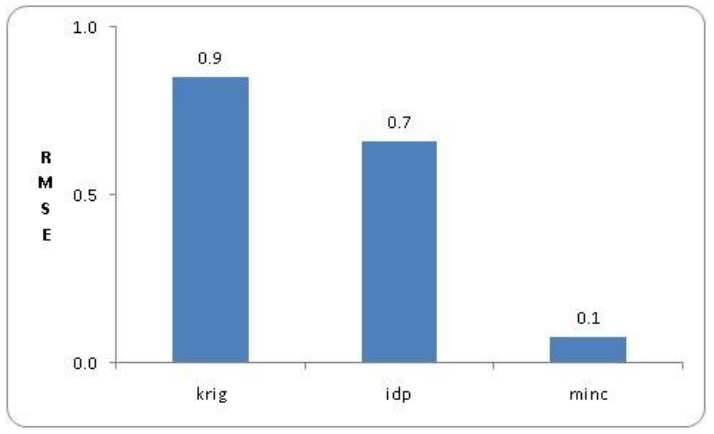

Gambar 8. RMSE kedalaman interpolasi dari ketiga interpolator pada skenario 2.

cukup membantu dalam menghasilkan kontur kedalaman yang lebih baik dan bebas dari 'manipulasi kartografis'. Namun, prinsip pengadaan 'data berlebih' dalam pembuatan peta batimetri bisa jadi merupakan pilihan yang perlu dilakukan, sehingga dapat diberlakukan sejumlah skenario pengolahan data untuk mendapatkan hasil yang terbaik. 
Studi ini telah mengimplementasikan dua skenario untuk menghasilkan kontur kedalaman dari tiga metode interpolasi. Hasilnya menunjukkan metode minimum curvature dapat memberikan kontur kedalaman yang akurat dibandingkan metode lainnya. Hasil implementasi skenario dua memperlihatkan, meskipun nilai akurasi metode Kriging tidak lebih baik dari minimum curvature, namun hasil interpolasinya dapat memberikan gambaran umum pola kedalaman di lokasi studi yang paling baik dari ketiga metode yang diuji.

Efektifitas dalam arti peningkatan akurasi dari setiap interpolator dapat ditingkatkan dengan memberikan perlakuan pada data input. Hal ini terlihat dari peningkatan akurasi yang dihasilkan oleh ketiga metode pada skenario 2 dimana banyak data perum direduksi sehingga hanya menyisakan data perum yang mewakili gambaran melintang (crossline) dari profil kedalaman yang diukur.

\section{KESIMPULAN DAN SARAN}

Nilai RMSE untuk ketiga metode yang dibandingkan cukup bervariasi untuk kedua skenario. Dari sudut pandang kartografis, metode Kriging efektif digunakan untuk memberikan gambaran pola kontur kedalaman, meskipun pada beberapa titik nilai hasil interpolasinya lebih rendah dibandingkan interpolator lain. Sementara itu, metode minimum curvature dapat memberikan hasil interpolasi kontur kedalaman yang akurat pada batas-batas titik perum, diluar batas itu, metode ini tidak dapat memberikan pola kontur kedalaman yang lebih baik daripada metode Kriging.

Studi ini memperlihatkan perlunya penanganan data agar pola suatu unsur spasial (kontur kedalaman) dapat ditampilkan secara lebih baik. Studi lanjutan dapat dilakukan dengan menguji ketiga interpolator untuk desain lajur perum yang berbeda dan metode uji yang lebih kompleks.

\section{DAFTAR PUSTAKA}

Abramowitz, M., and I. Stegun. 1972. Handbook of Mathematical Functions, Dover Publications, New York.

Briggs, I. C. 1974. Machine Contouring Using Minimum Curvature, Geophysics, 39(1):39-48.

Chapra, S.C., dan R.P. Canale. 1991. Metode Numerik untuk Teknik: dengan penerapan pada komputer pribadi. Terjemahan oleh S. Sardy dan Lamyarni, I.S. Penerbit Universitas Indonesia, Jakarta.

Cressie, N. A. C. 1990. The Origins of Kriging. Mathematical Geology, 22:239-252.

Cressie, N. A. C. 1991. Statistics for Spatial Data, John Wiley and Sons, Inc., New York, 900 pp.

Davis, J. C. 1986. Statistics and Data Analysis in Geology, John Wiley and Sons, New York.

Deutsch, C.V., and A. G. Journel. 1992. GSLIB - Geostatistical Software Library and User's Guide, Oxford University Press, New York, 338 pp.

Franke, R. 1982. Scattered Data Interpolation: Test of Some Methods. Mathematics of Computations, 33(157):181-200.

Isaaks, E. H., and R. M. Srivastava. 1989. An Introduction to Applied Geostatistics, Oxford University Press, New York, 561 pp.

Journel, A.G., and C. Huijbregts. 1978. Mining Geostatistics, Academic Press, 600 pp. 
Journel, A.G. 1989. Fundamentals of Geostatistics in Five Lessons, American Geophysical Union, Washington D.C.

Keckler, D. 1994. Surfer for Windows, User Guide. Golden Software, inc. Colorado.

Largueche, F.Z.B. 2006. Estimating Soil Contamination with Kriging Interpolation Method. American Journal of Applied Sciences: Vol. 3, No. 6. Hal:1894-1898.

Li, Z., Q. Zhu, and C. Gold. 2005. Digital Terrain Modelling. Principles and Methodology. CRC Press.

Press, W.H., B.P. Flannery, S. A. Teukolsky, and W. T. Vetterling. 1988. Numerical Recipes in C, Cambridge University Press.
Shamsudduha, M. 2007. Spatial Variability and Prediction Modeling of Groundwater Arsenic Distributions in the Shallowest Alluvial Aquifers in Bangladesh. Journal of Spatial Hydrology, 7(2).

Smith, W. H. F., and P. Wessel. 1990. Gridding with Continuous Curvature Splines in Tension. Geophysics, 55(3):293-305

van Beers, W.C.M, dan J. P.C. Kleijnen. 2004. Kriging Interpolation in Simulation: A Survey. Proceedings of the Winter Simulation Conference

Yang, C.S, S.P. Kao, F.B. Lee dan P.S. Hung. 2004. Twelve Different Interpolation Methods: A Case Study of Surfer 8.0. Proceedings of XXth ISPRS Congress. Commission II. Istanbul. Turkey. 